\title{
The Prevalence of People Underwent Appendectomy Procedure in Saudi Arabia
}

\author{
Ziyad Ali s Alosayfir ${ }^{1}$, Abdulaziz Ayed M Alshammari ${ }^{1}$, Yousef Ateeg Awad Alsadi ${ }^{1}$, Hamoud \\ Meshal Farhan Alshammari ${ }^{1}$, Hussam Salem Alshammari ${ }^{1}$, Marwan ahmed jaafari ${ }^{2}$, Saleh Ali \\ Saleh Kharshan AL Ghamdi ${ }^{3}$, Firas osama alghaffari ${ }^{4}$ \\ College of Medicine University of Hail ${ }^{1}$, College of Medicine Prince sattam ben Abdulaziz \\ University $^{2}$, Rawalpindi Medical College ${ }^{3}$, Mansoura university Egypt ${ }^{4}$ \\ Corresponding author: ziyad Ali s alosayfir, E-mail: Dr.zeiad.alo@gmail.com, Phone no: +966537700578
}

\begin{abstract}
Background despite the modern life and the availability of knowledge, the prevalence of people who have had appendectomy procedures is increasing these days in Saudi Arabia in the previous years for multiple different risk factors. Knowing the prevalence of people who underwent appendectomy procedure in Saudi Arabia and comparing it with other countries could provide useful information about these risk factors and how to avoid them. Objectives: This study was done to collect information upon and investigate the prevalence people under went appendectomy procedure in Saudi Arabia. Methods: A cross-sectional study was carried out on 864 participants from different social media platforms to investigate the prevalence of people who have had an appendectomy procedure in Saudi Arabia from February to April 2018. Results: $41.1 \%$ of the participants knew some information about appendicitis, $8.1 \%$ of the participants have had an appendectomy procedure, $33.3 \%$ of the participants who had an appendectomy procedure suffered from post-surgery complication, $29.7 \%$ of the participants suffered from gastrointestinal diseases. Recently, $41.4 \%$ of the participants do not eat food rich in fibers and $37.7 \%$ of the participants have a positive family history of appendectomy Conclusion: At the end of this study, there were an increased number of people who have had an appendectomy procedure in Saudi Arabia.
\end{abstract}

Keywords: appendicitis, appendectomy, complications.

\section{INTRODUCTION}

The vermiform appendix is a about a tubular diverticulum which comes from the posteromedial wall of the cecum which is about $30 \mathrm{~mm}$ below the ileocecal valve location (1). The appendix's tip is variable in its location and might lie in a retroileal, retrocecal, subcecal, preileal or pelvic location. This variability in the appendix location may influence and affects the presentation of appendicitis clinically ${ }^{(2)}$. Appendicitis is the inflammation of the vermiform appendix which is the most common cause of acute abdomen in both adults and children all over the world ${ }^{(3)}$. Appendectomy procedure is the gold standard and best choice in treating the acute appendicitis whereby, the inflamed appendix is removed to help the patients avoiding the complications that may rise from appendicitis ${ }^{(3)}$. If untreated, appendicitis may lead to several clinical complications, which may be cause death to the patients eventually. Appendectomy is one of the most common surgical procedures performed worldwide ${ }^{(4)}$. There are many clinical studies that may show the best practice in the management of acute appendicitis ${ }^{(5)}$. An appendectomy is a fairly easy, simple and common procedure. However, there are some risks associated with the surgery, including infection, bleeding, injury to the nearby organs and blocked bowels. It's very important to know that the risks of an appendectomy procedure are much less severe than the risks associated with untreated appendicitis which may be fetal. An appendectomy needs to be done as quickly as possible to prevent abscesses and peritonitis from developing ${ }^{(6)}$.

\section{MATERIALS AND METHODS}

A cross-sectional study involving 864 participants all over Saudi Arabia was done in the period between February to April 2018. The sample size for this study was selected and distributed randomly. Self-administered questionnaires were developed after a careful review of literature on the subject and it included 9 questions submitted to people in Saudi Arabia. The questionnaires had two parts. Part one; demographical data that includes age, gender and marital status. Part two; the participants were asked whether they have any information about appendicitis or not, whether they have had an appendectomy procedure or 
not, whether they have faced any complications after appendectomy or not, whether they have been suffering from gastrointestinal tract diseases lately or not, whether they eat food that it is rich in fibers or not and has any one of the family member had an appendectomy procedure or not. Data were collected by through a survey that was distributed through a website-link through participants in Saudi Arabia in different social media sites and platforms. Statistics were descriptively used to describe the answers of the participants in the study using numbers and percentages.

The answers were compared for different questions within the different groups using Pearson chi-square test. Statistical significance was set at $p<0.05$ and analysis was performed using IBM SPSS statistics, version 23 (IBM, Armonk, NY, USA).

The study was done after approval of ethical board of University of Hail.

\section{RESULTS}

A total of 864 participant women from all over Saudi Arabia were participated in the study and
$44.9 \%$ of them were between the ages of 20 to 30 years old, $24.1 \%$ were between 30 to 40 years old, $21 \%$ were between 10 to 20 years old and only $9.3 \%$ were more than 40 years old (Table1). More than half of the participants $57.6 \%$ were single and $42.4 \%$ were married (Table 2). Regarding participants who know any information about appendicitis, $41.1 \%$ of the participants were aware about appendicitis (Table 3). Regarding the participants who have had an appendectomy procedure, $8.1 \%$ of the participants had an appendectomy procedure (Table 4). As regarding post appendectomy procedure complications, $33.3 \%$ of the participants suffered from complications following the procedure (Table 5). Concerning gastrointestinal diseases, $29.7 \%$ of the participants have been suffering from gastrointestinal tract diseases lately (Table 6). $58.6 \%$ of the participants eat food that is rich in fibers (Table 7). $37.7 \%$ of the participants have a family member who has had an appendectomy procedure (Table 8).

Table (1): Age distribution of the participants:

\begin{tabular}{|l|l|l|}
\hline Age & Frequency & Percent \\
\hline $1-10$ & 6 & 0.7 \\
\hline $10-20$ & 191 & 21 \\
\hline $20-30$ & 408 & 44.9 \\
\hline $30-40$ & 219 & 24.1 \\
\hline$>40$ & 84 & 9.3 \\
\hline Total & 864 & 100 \\
\hline
\end{tabular}

Table (2): Marital status and gender of the participants:

\begin{tabular}{|l|l|l|}
\hline $\begin{array}{l}\text { Marital } \\
\text { status }\end{array}$ & Frequency & Percent \\
\hline Single & 523 & 57.6 \\
\hline Married & 385 & 42.4 \\
\hline Total & 908 & 100 \\
\hline Gender & & \\
\hline Male & 615 & 67.7 \\
\hline Female & 293 & 32.3 \\
\hline Total & 864 & 100 \\
\hline
\end{tabular}

Table (3): Available knowledge about appendicitis:

\begin{tabular}{|l|l|l|}
\hline $\begin{array}{l}\text { Know any information about } \\
\text { appendicitis }\end{array}$ & Frequency & Percent \\
\hline Yes & 355 & 41.1 \\
\hline No & 509 & 58.9 \\
\hline Total & 864 & 100 \\
\hline
\end{tabular}


Table (4): Frequency of an appendectomy procedure:

\begin{tabular}{|l|l|l|}
\hline Had an appendectomy procedure & Frequency & Percent \\
\hline Yes & 70 & 8.1 \\
\hline No & 794 & 91.9 \\
\hline Total & 864 & 100 \\
\hline
\end{tabular}

Table (5): post appendectomy procedure complications:

\begin{tabular}{|l|l|l|}
\hline $\begin{array}{l}\text { Post appendectomy procedure } \\
\text { complications }\end{array}$ & Frequency & Percent \\
\hline Yes & 23 & 33.3 \\
\hline No & 47 & 66.7 \\
\hline Total & 70 & 100 \\
\hline
\end{tabular}

Table (6): Participants who suffer from gastrointestinal tract diseases lately:

\begin{tabular}{|l|l|l|}
\hline $\begin{array}{l}\text { Suffer from gastrointestinal tract } \\
\text { diseases lately }\end{array}$ & Frequency & Percent \\
\hline Yes & 257 & 29.7 \\
\hline No & 607 & 70.3 \\
\hline Total & 864 & 100 \\
\hline
\end{tabular}

Table (7): Eating food rich in fibers

\begin{tabular}{|l|l|l|}
\hline Eat food rich in fibers & Frequency & Percent \\
\hline Yes & 506 & 58.6 \\
\hline No & 358 & 41.4 \\
\hline Total & 864 & 100 \\
\hline
\end{tabular}

Table (8): positive family history of appendectomy:

\begin{tabular}{|l|l|l|}
\hline $\begin{array}{l}\text { Positive family history of } \\
\text { appendectomy }\end{array}$ & Frequency & Percent \\
\hline Yes & 326 & 37.7 \\
\hline No & 538 & 62.3 \\
\hline Total & 864 & 100 \\
\hline
\end{tabular}

\section{DISCUSSION}

In the present study, we found that there were an increased number of people who have had an appendectomy procedure in Saudi Arabia with $8.1 \%$ affection rate. An appendectomy procedure (also known as appendicectomy) is the surgical intervention to remove an appendix, generally performed under emergency conditions when the patient is suffering from acute appendicitis. Recently, laparoscopic appendectomy has been more common in the increasing consensus over the traditional open surgeries procedures (4). Making a diagnosis of appendicitis was most likely in a patient with the presence of pain, vomiting, and fever. Intense and severe pain at the peri-umbilical area to the right lower quadrant with rigidity is classical signs and symptoms of appendicitis ${ }^{(7)}$. Appendix in the retrocecal region in the patient with appendicitis experiences pain on extension of right hip joint due to tension resulting from it (7). There are many anatomical factors producing inflammation may be due to the presence of fecolith, appendix receiving blood by an end artery, or even deficiency in the muscular wall. Sometimes, blockage of theappendix is due to deposition of thick mucus inside it. The gender-based lifetime risk of acute appendicitis reported in males and females are $8.6 \%, 6.7 \%$, respectively with the lifetime risk of having an appendectomy procedure reported to be $12 \%$ for men and $25 \%$ for women ${ }^{(8,9)}$. Regarding knowledge about appendicitis, only $41.1 \%$ of the participants in 
this study knew some information about it. A large number of participants in this study who have had an appendectomy suffered from postsurgery complications. There were some risk factors which lead to appendicitis among the participants in this study such as suffering from gastrointestinal diseases recently with affection rate of $29.7 \%$, not eating food that rich in fibers with affection rate of $41.1 \%$ and having a positive family history of appendectomy with $37.7 \%$ affection rate. The limitation of this study was that we could not compare most of our results with other findings that were done in Saudi Arabia since we could not found any similar topic and our sample size was not that large enough.

\section{CONCLUSION}

We can conclude that there are an increased number of people who have had an appendectomy procedure in Saudi Arabia. Doctors and the community should teach, provide people with essential and simple information about appendicitis and how to identify the early symptoms of it. People also should seek medical care once they feel any of appendicitis symptoms and don not delay going to the emergency department.

\section{REFRENCES}

1. Buschard K, Kjaeldfaard A (1973): Investigation and analysis of the position, fixation,length and embryology of the vermiform appendix. Acta Chir Scand., 139(3):293-298.
2. Guidry SP, Poole GV (1994): The anatomy of appendicitis. Am Surg journal.=, 60(1):68-71.

3. O'Connell PR (2008): The vermiform appendix. Bailey and Loveâ Short Practice of Surgery, 25th ed. pp-12041218.

www.ijsurgery.com/index.php/isj/artic le/view/129

4. Piccinni G, Sciusco A, Gurrado A et al. (2012): The "BASE-FIRST" technique in laparoscopic appendectomy. J MinimalAccess Surg., 8(1):6-8.

5. Fitzmaurice GJ, McWilliams B, Hurreiz $\mathrm{H}$ et al. (2011): Antibiotics versus appendectomy in the management of acute appendicitis: a review of the current evidence. Can J Surg., 54(5):307-314

6. Steven K (2016): appendectomy. Health line editorial team. Available at: https://www.healthline.com/health/app endectomy\#procedure

7. Birnbaum BA, Wilson SR (2000): Appendicitis at the millennium. Radiology, 215(2): 337- 348.

8. Rothrock SG, Pagane J (2000): Acute appendicitis in children: Emergency department diagnosis and management. Ann Emerg Med., 36(1):39-51.

9. Khairy G (2009): Acute appendicitis: Is removal of a normal appendix still existing and can we reduce its rate? Saudi J Gastroenterol., (3):167-170. 